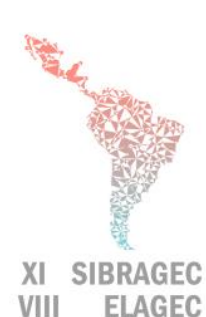

VIII ELAGEC

\section{SIMPÓSIO BRASILEIRO DE GESTÃO E ECONOMIA DA CONSTRUÇÃO \\ VIII ENCUENTRO LATINOAMERICANO DE GESTIÓN \\ Y ECONOMÍA DE LA CONSTRUCCIÓN}

Do conhecimento à ação: práticas avançadas de gestão da produção

Londrina, Paraná, Brasil. 23 a 25 de Outubro de 2019

\title{
ARQUITETURA RESIDENCIAL PARA TERCEIRA IDADE: UM ESTUDO DE CASO NO RESIDENCIAL CIDADE MADURA
}

\author{
ARAÚJO, Nelma Mirian Chagas (1); SOARES, Inara Beatriz Rodrigues (2) \\ (1) IFPB - Campus João Pessoa, Tel. (83) 3612 1282, e-mail: nelmamca@ gmail.com (2) IFPB - \\ Campus João Pessoa, e-mail: rodriguesinara43@gmail.com
}

\begin{abstract}
The aging process goes far beyond a chronological classification. That is, causes psychological and biological changes that vary according to the reality of the different groups socioeconomic, and therefore requires changes in the environment built to guarantee the well-being of the elderly. However, there are few buildings that are willing to of the older Brazilian public, and when we narrow the search area to the state of the Paraiba, the number becomes even smaller. Within this context, the present work addresses the independent residential architecture for the elderly; investigating the main deficits caused by old age and the changes demanded by it in the physical environment residential housing in Mature City under the NBR 9050 perspective. Finally, it can be seen that the condominium does not present a completely satisfactory architecture, but provides a space where the residents are protected, integrated and encouraged to stay active and overturn the prejudiced view that classifies them as incapable.
\end{abstract}

Keywords: Accessibility. Mature City Project. Old man. Built Environment.

\section{INTRODUÇÃOO}

A temática abordada neste artigo é a arquitetura residencial para terceira idade independente. Nesse sentido, foi feita uma avaliação do ambiente físico das habitações do Condomínio Residencial Cidade Madura sob a ótica da NBR 9050 (ABNT, 2015).

$\mathrm{O}$ aumento da expectativa de vida da população tem sido uma realidade presente no mundo todo, inclusive no Brasil, devido a diversos fatores, como avanço tecnológico, evolução científica, mudança de hábitos etc. "Diversos estudiosos têm se preocupado com essa questão e estima-se que em 2025 o Brasil será o sexto país com a maior população de idosos no mundo" (BRUM; TOCANTINS e SILVA, 2005 apud QUEIROZ, 2010, p. 16).

De acordo com o Estatuto do Idoso, Art. 37: "O idoso tem direito à moradia digna, no seio da família natural ou substituta, ou desacompanhado de seus familiares, quando assim o desejar, ou, ainda, em instituição pública ou privada"; vale ressaltar também o Art. 38, que garante, entre outras coisas, a "eliminação de barreiras arquitetônicas e urbanísticas, para garantia de acessibilidade ao idoso".

Entretanto, boa parte do mercado da construção civil não tem acompanhando tal mudança e, como consequência disso, a população sofre com a falta de edifícios residenciais adaptados às suas necessidades. O Brasil tem cerca de 13 milhões de pessoas com mais de 60 anos, que são responsáveis por um terço dos atendimentos de lesões traumáticas nos hospitais, segundo o SUS - Sistema Único de Saúde. Aproximadamente 75\% dessas lesões acontecem nas próprias casas dos pacientes, em quedas que poderiam ser evitadas 
em ambientes mais favoráveis, com um índice de melhoria da qualidade de vida bastante apreciável, já que 34\% das quedas gera algum tipo de fratura (BARROS, 2000 apud VINAGRE, 2016, p. 5).

Torna-se, então, de fundamental importância, compreender e atender as necessidades espaciais dos idosos, fazendo com que as leis sejam devidamente aplicadas e garantindo uma boa qualidade de vida para esse grupo social que tem constituído uma parte cada vez maior da população brasileira.

\section{A TERCEIRA IDADE}

Segundo o Estatuto do Idoso, toda pessoa com 60 anos ou mais é considerada idosa, enquanto que para a Organização Mundial da Saúde (2003) o limite mínimo pode variar: 60 anos ou mais em países em desenvolvimento e 65 anos ou mais em países desenvolvidos.

Apesar do conceito ser tratado de maneira tão simplificada, deve-se reconhecer que o processo de envelhecimento vai muito além de uma classificação cronológica. Isto é, provoca alterações psicológicas e biológicas que variam em função da realidade dos diferentes grupos sociais e econômicos. "Envelhecer é um processo natural que caracteriza uma etapa da vida do homem e dá-se por mudanças físicas, psicológicas e sociais que acometem de forma particular cada indivíduo com sobrevida prolongada" (MENDES et al., 2005, p. 2).

"A capacidade funcional pode ser definida como a manutenção da habilidade para realizar atividades básicas da vida diária (ABVD) e atividades instrumentais da vida diária (AIVD), necessárias e suficientes para a manutenção de uma vida independente e autônoma" (FERREIRA et al., 2010, p. 514).

\section{ACESSIBILIDADE EFETIVA DO AMBIENTE}

Segundo a NBR 9050 (ABNT, 2015), acessibilidade é a "possibilidade e condição de alcance, percepção e entendimento para a utilização com segurança e autonomia de edificações, espaço, mobiliário, equipamento urbano e elementos".

Conceber, portanto, um ambiente acessível, é basicamente proporcionar o fácil acesso ao espaço determinado; entretanto, tal afirmação torna-se relativa, uma vez que, sob as mesmas condições, nem todos os públicos conseguem ingressar no ambiente.

"Para responder com propriedade qual é a acessibilidade de um sistema é necessário compreender: a quem é acessível, em que medida e sob que condições. Só assim será possível afirmar qual é a Acessibilidade Efetiva" (BAPTISTA, 2011, p. 62).

"A Funcionalidade é um termo que engloba todas as funções do corpo, atividades e participação; de maneira similar, incapacidade é um termo que inclui deficiências, limitação da atividade ou restrição na participação" (OMS, 2003).

"Dentre os fatores contextuais está o ambiente construído. Deste modo, quanto maior a adequação do ambiente construído ao usuário, maior será a qualidade de vida das pessoas" (BAPTISTA, 2011, p. 69).

Quando abordada pela OMS (2003), a funcionalidade de um indivíduo num domínio específico é uma interação ou relação complexa entre a condição de saúde e os fatores ambientais e pessoais. Há uma interação dinâmica entre essas entidades: uma intervenção 
num elemento pode, potencialmente, modificar um ou vários outros elementos. Essas interações são específicas e nem sempre ocorrem numa relação unívoca previsível.

\section{ESTUDO DE CASO}

O Programa Habitacional Cidade Madura, desenvolvido pela Secretaria de Desenvolvimento Humano (SEDH), é o primeiro no Brasil a oferecer um condomínio público exclusivo para idosos e inteiramente projetado para suas necessidades específicas. Em João Pessoa, o Residencial Cidade Madura, inaugurado em junho de 2014, é um condomínio horizontal elaborado pela equipe técnica do setor de Projetos da Companhia Estadual de Habitação Popular (CEHAP), liderada pelos arquitetos Júlio Gonçalves e Rafaela Mabel Silva Guedes.

A propriedade possui área total de 5,07 ha e localiza-se no Conjunto Habitacional Cidade Verde, no bairro de Mangabeira. O local, segundo a CEHAP, foi escolhido por integrar a malha urbana, apresentar acesso fácil, infraestrutura básica, entre outros aspectos. $\mathrm{O}$ empreendimento consiste em 40 unidades residenciais com $54 \mathrm{~m}^{2}$ cada, onde podem ser acomodados um ou dois idosos (casal) por habitação e a presença da família é liberada apenas para visitas. Ademais, conta com uma unidade de saúde, praça, horta comunitária, centro de vivência, academia ao ar livre e pista de caminhada (Figura 1).

\section{Figura 1: Mapa da Proposta Urbanística do Residencial Cidade Madura}

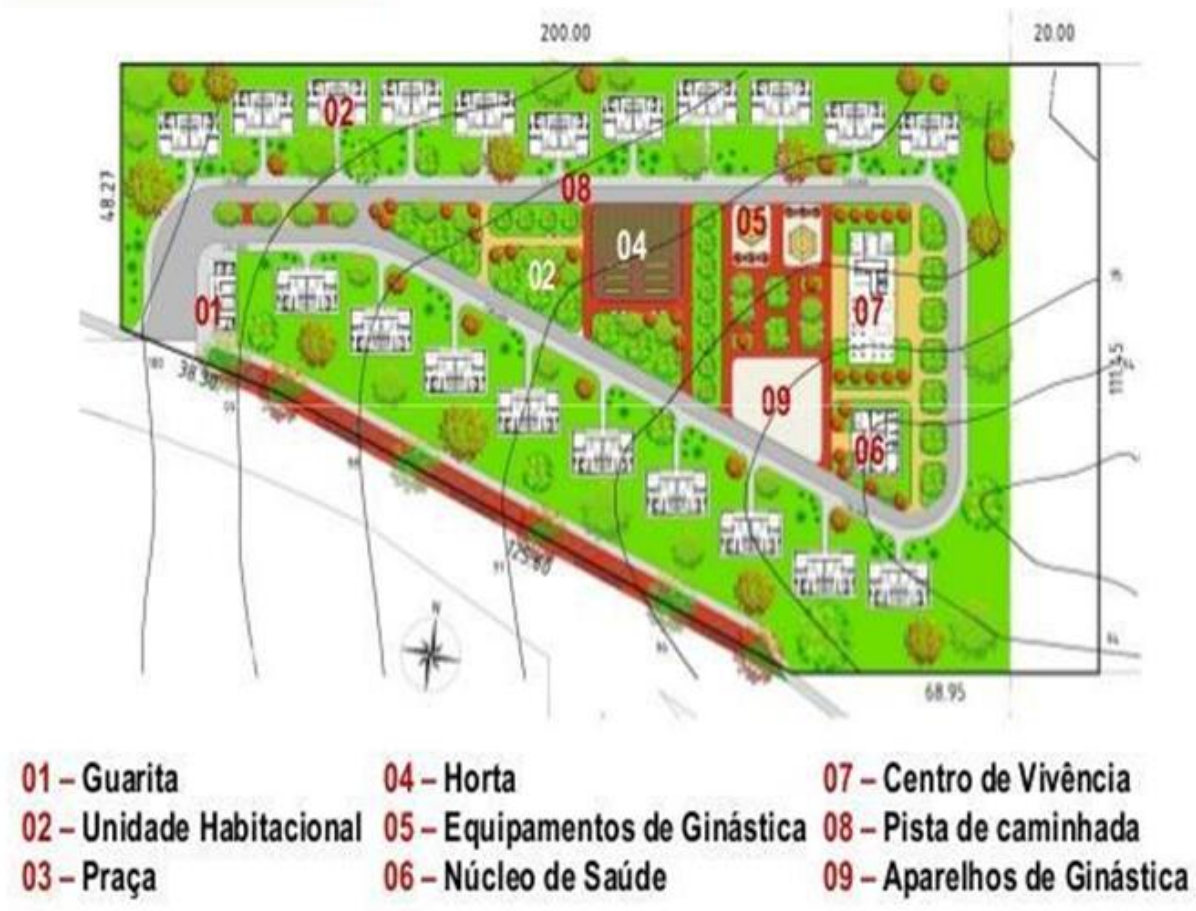

Fonte: CEHAP (2012)

O residencial ainda apresenta particularidades no que diz respeito ao atendimento do público, pois prioriza os idosos sem oportunidade de qualidade de vida e determina requisitos para participação no programa, tais como:

- O idoso precisa ter 60 anos ou mais e deve morar sozinho ou com o companheiro(a);

- Precisa receber até 5 salários mínimos e ter condições de se sustentar; 
SIBRAGEC - ELAGEC 2019 - de 23 a 25 de Outubro - LONDRINA - PR

- Deve ter autonomia para poder realizar as atividades da vida diária;

- Em caso de desistência ou falecimento, o(a) companheiro(a) só poderá permanecer no condomínio se tiver mais de 60 anos.

Em caso de perda de autonomia, a família é comunicada e o idoso é encaminhado para uma ILPI (Instituição de Longa Permanência para Idosos), por não se encaixar mais nos critérios exigidos para participar do programa, ou se houver outro tipo de descumprimento dos requisitos, a propriedade da casa é devolvida ao Estado e um novo morador é convidado a participar do programa.

\section{METODOLOGIA}

A coleta de dados se deu em dois momentos: no primeiro momento, com relação à pesquisa bibliográfica; no segundo, com relação à pesquisa documental e de campo.

Na pesquisa bibliográfica, os dados foram coletados através de fichas resumos oriundas de teses, dissertações, monografias, artigos e livros que tinham relação com o tema da pesquisa.

Já na pesquisa documental, houve a análise das especificações de serviço e dos projetos arquitetônicos das edificações que compõem o Projeto Cidade Madura, enquanto que na pesquisa de campo, os dados foram coletados por meio de roteiros de observação, os quais foram elaborados a partir dos itens que compõem a NBR 9050 (ABNT, 2015) e registros fotográficos dos itens avaliados, em visitas in loco realizadas pelas pesquisadoras.

A partir da planta baixa das habitações (Figura 2) foi possível coletar os dados complementares para realizar a comparação com as normas técnicas de referência, de modo a verificar a conformidade dos itens. 
SIBRAGEC - ELAGEC 2019 - de 23 a 25 de Outubro - LONDRINA - PR

Figura 2: Planta baixa da unidade habitacional

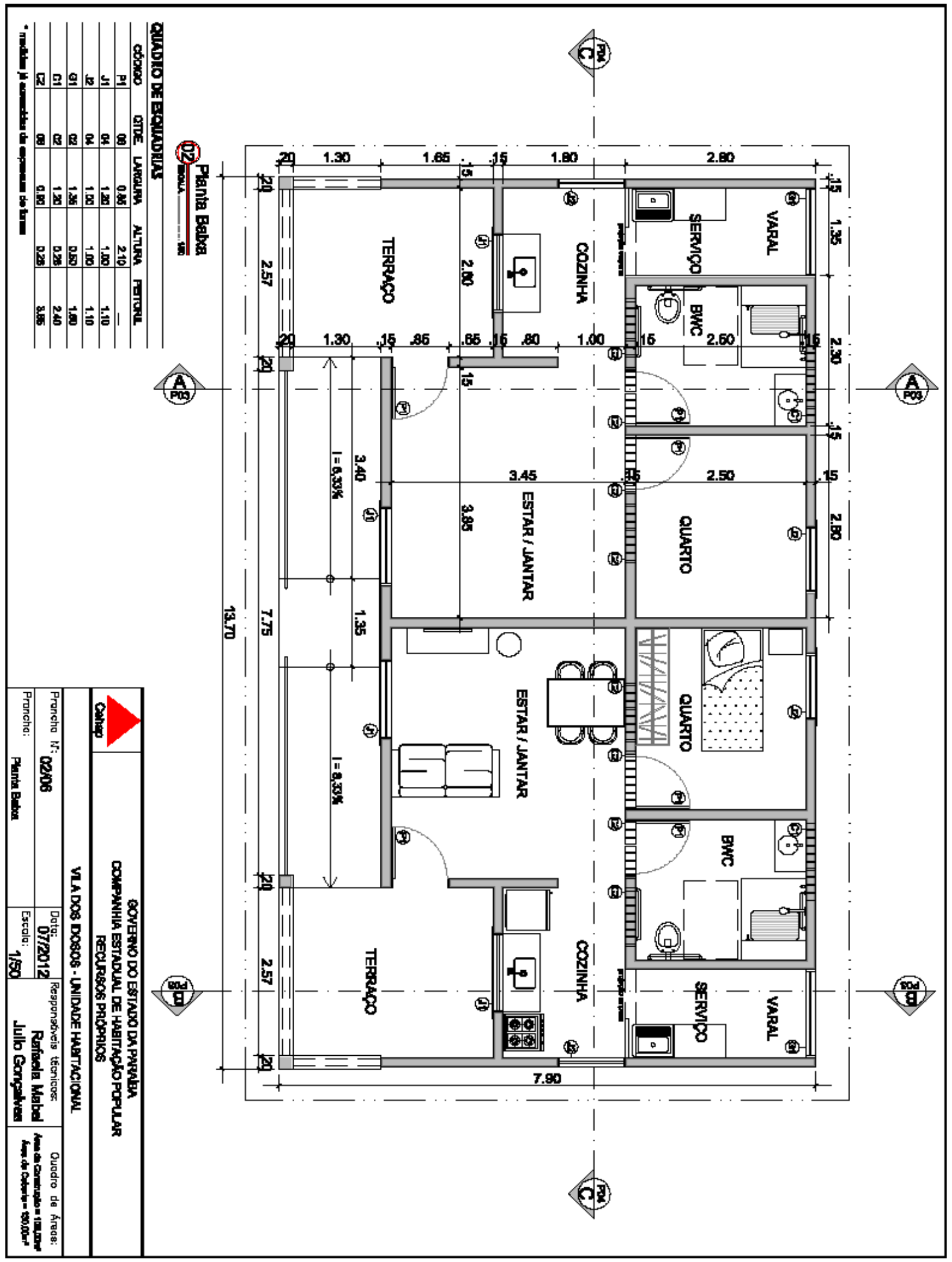

Fonte: CEHAP (2012) 
SIBRAGEC - ELAGEC 2019 - de 23 a 25 de Outubro - LONDRINA - PR

\section{RESULTADOS E CONSIDERAÇÕES}

Como pode ser observado na planta baixa (Figura 2), as unidades residenciais são distribuídas duas a duas de forma geminada e espelhada. Cada casa possui seis cômodos: 1 quarto, 1 banheiro, 1 cozinha, 1 sala de estar/ jantar, 1 área de serviço e 1 terraço. Dentre os ambientes, somente o banheiro é adaptado para pessoa com deficiência (PcD), os demais não são adaptados para acesso de cadeira de rodas, pois não possuem dimensões mínimas para a circulação e giro de cadeira de rodas.

A seguir são apresentadas fotos de algumas das edificações que compõem o Projeto Cidade Madura (Figuras 3 a 6) e os principais resultados quanto ao atendimento à NBR 9050 (ABNT, 2015).

Figura 3: Unidades residenciais

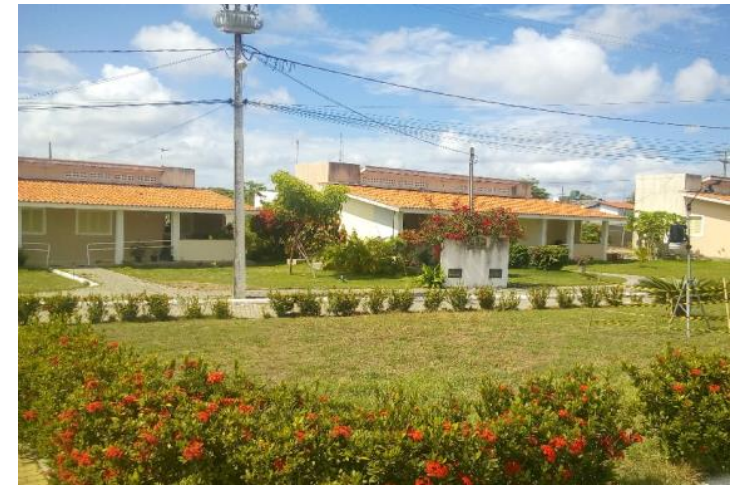

Fonte: Acervo próprio (2019)

Figura 5: Academia ao ar livre

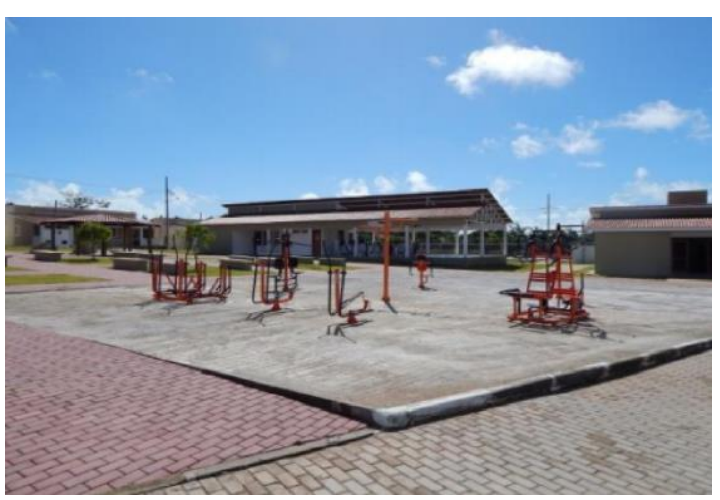

Fonte: Acervo próprio (2019)
Figura 4: Centro de Vivência

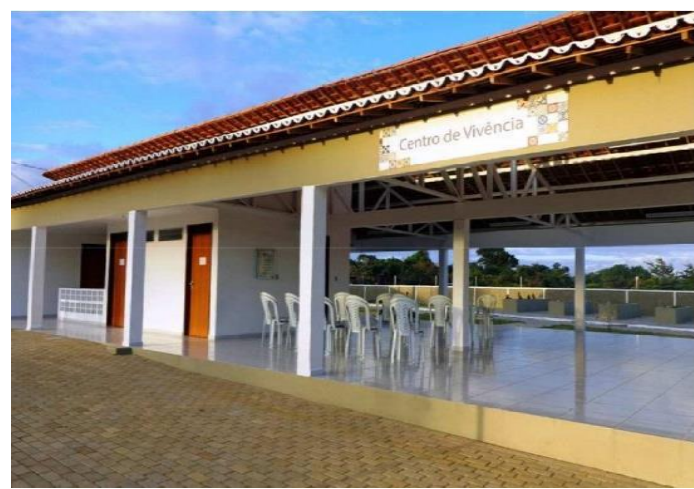

Fonte: Acervo próprio (2019)

Figura 6: Administração

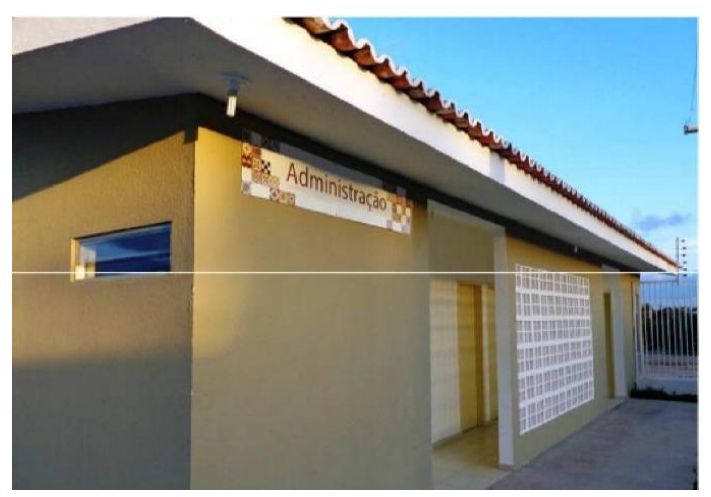

Fonte: Acervo próprio (2019)

\section{Rampa de Acesso}

$\mathrm{O}$ acesso a cada moradia é feito por uma rampa com 3,40 $\mathrm{m}$ de comprimento, 1,30 $\mathrm{m}$ de largura e inclinação de 8,33\%, adequando-se à NBR 9050 (ABNT, 2015). Entretanto, a largura apresentada encontra-se acima do mínimo admissível de 1,20 m, mas abaixo do valor recomendável de $1,50 \mathrm{~m}$. Ainda assim, levando em consideração que o fluxo cotidiano de pessoas é pequeno, a medida atual não representa uma barreira dentro do ambiente construído. 
Apenas um dos lados da rampa possui corrimão, sendo esse de duas alturas, porém não se prologam paralelamente ao piso reto antes do início da rampa, é descontínuo e interrompido por um pilar não indicado em planta. Além disso, não há elementos de segurança, como guarda-corpo - exigido nos casos de falta de parede lateral - e guia de balizamento (Figura 7).

\section{Figura 7: Vista lateral da rampa de entrada}

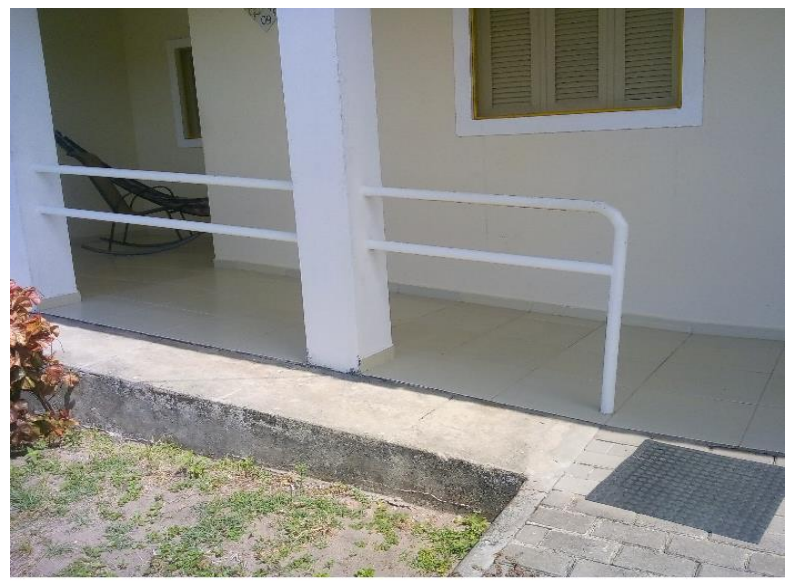

Fonte: Acervo próprio (2019)

\section{Portas}

Todas as portas das casas (de entrada e internas) possuem 0,85 $\mathrm{m}$ de largura, superando o valor mínimo recomendado pela NBR 9050 (ABNT, 2015), que é de 0,80 m. Porém, a abertura de aceso para a área de serviço possui uma largura menor do que o indicado, a qual dificulta a passagem dos moradores que eventualmente precisam transitar pela área com uma pilha de roupas e, consequentemente, gera um ponto de risco à segurança.

Com relação às maçanetas, constatou-se que os seus formatos arredondados dificultam a pegada do idoso e exigem o movimento de torção, ao contrário do modelo alavanca indicado pela NBR 9050 (ABNT, 2015); além disso, na parte de trás da porta do banheiro (Figura 8) não há puxador horizontal para possibilitar o apoio e auxiliar na movimentação da porta.

Figura 8: Porta do banheiro

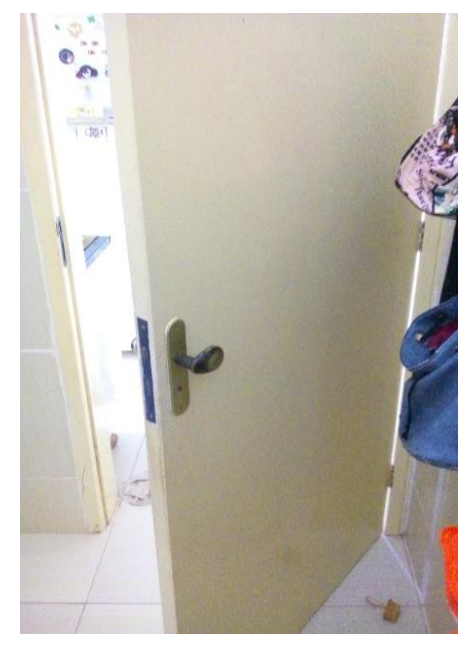

Fonte: Acervo próprio (2019) 


\section{Banheiros}

A porta do banheiro deveria abrir para fora do cômodo, facilitando a prestação de socorro no caso do idoso sofrer algum acidente, como por exemplo uma queda ou desmaio, que impeça a abertura da porta pelo lado de dentro.

No que se refere às barras de apoio necessárias para garantir o uso seguro e autônomo, existem duas barras metálicas horizontais próximas à bacia sanitária, uma na parede de fundo e uma na parede lateral, ambas possuem cerca de $0,80 \mathrm{~m}$ de extensão. Porém, o condomínio descumpre a NBR 9050 (ABNT, 2015) devido à falta não só da barra vertical que deveria ser fixada na parede lateral um pouco acima do apoio horizontal existente, como das barras que ficariam nas laterais do lavatório, podendo ser horizontais e/ou verticais.

Já dentro do boxe, pode-se afirmar que foram atendidas as medidas mínimas de comprimento e largura definidas por norma $(0,90 \mathrm{~m} \times 0,95 \mathrm{~m})$. Do mesmo modo, foi seguida a exigência de um banco com cantos arredondados, superfície antiderrapante impermeável e profundidade e comprimento satisfatórios (Figura 9). Cabe destacar que todas as barras indicadas na norma são encontradas: uma barra vertical na parede onde está fixado o banco, uma horizontal e uma vertical na parede que contém a torneira e o chuveiro.

\section{Figura 9: Banco articulado dentro do box}

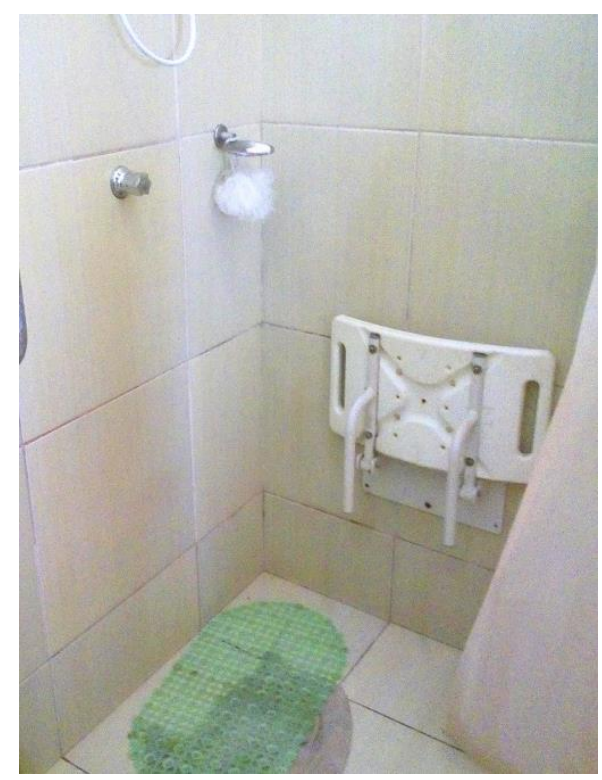

Fonte: Acervo próprio (2019)

\section{CONCLUSÕES}

Dos itens abordados neste artigo, relativos à adequação das habitações do Projeto Cidade Madura à NBR 9050 (2015), constatou-se que nenhum deles está em conformidade total com a referida norma. Todos atendem de forma parcial às disposições da norma, sendo as situações mais críticas encontradas nas rampas de acessos, nas portas e nos banheiros.

Por fim, conclui-se que o projeto é um avanço em termos de moradias específicas para o idoso, todavia, necessita de ajustes para que atenda às recomendações da NBR 9050 (ABNT, 2015), sendo esses ajustes relevantes para que os demais projetos a serem 
SIBRAGEC - ELAGEC 2019 - de 23 a 25 de Outubro - LONDRINA - PR

implementados nas cidades paraibanas atendam, em sua totalidade, à NBR 9050 (ABNT, 2015).

\section{REFERÊNCIAS}

ASSOCIAÇÃO BRASILEIRA DE NORMAS TÉCNICAS. NBR 9050 - Acessibilidade a edificações, mobiliário e equipamentos urbanos. Rio de Janeiro, 2015.

BAPTISTA, A. H. N. Critérios para uma teoria de acessibilidade efetiva. In: MONT’ALVÃO, C.; VILLAROUCO, V. (org.). Um novo olhar para o projeto: a ergonomia no ambiente construído. Teresópolis: $2 \mathrm{AB}, 2011$.

COMPANHIA ESTADUAL DE HABITAÇÃO POPULAR. Projeto Cidade Madura. João Pessoa: CEHAP, 2012.

FERREIRA, O. G. L. et al. O envelhecimento ativo sob o olhar de idosos funcionalmente independentes. Revista da Escola de Enfermagem da USP, São Paulo, v. 44, n. 4, p. 10651069, 2010.

MENDES, M. R. S. S. B. et al. A situação social do idoso no Brasil: uma breve consideração. Acta Paulista de Enfermagem, São Paulo, n. 18, v. 4, p. 422-426, 2005.

ORGANIZAÇÃO MUNDIAL DA SAÚDE. CIF: Classificação Internacional de Funcionalidade, Incapacidade e Saúde. São Paulo: Universidade de São Paulo, 2003.

QUEIROZ, G. A. Qualidade de vida em instituições de longa permanência Para Idosos: considerações a partir de um modelo alternativo de assistência. 2010. 140 f. Dissertação (Mestrado em Psicologia) - Departamento de Psicologia, Universidade Federal de São João Del Rei, São João Del Rei, 2010.

VINAGRE, A. P. Residência para a terceira idade. Revista Especialize On line IPOG. Goiânia, 12. ed., v. 01, dez. 2016. Disponível em: <https://www.ipog.edu.br/revista-especializeonline/edicao-n12-2016/residencia-para-a-terceira-idade/>. Acesso em: 25 jan. 2019.

\section{AGRADECIMENTOS}

À CEHAP, pela viabilização da pesquisa através do fornecimento de dados. 